\title{
Caracterização fenotípica e genotípica de progênies de pupunheira para palmito(1)
}

\author{
Gilberto Ken-Iti Yokomizo(2) e João Tomé de Farias Neto ${ }^{(3)}$
}

\begin{abstract}
Resumo - A pupunheira (Bactris gasipaes H.B.K.) é considerada a espécie com maior potencial de produção de palmitos, em substituição aos tradicionais açaí (Euterpe oleracea Mart.) e juçara (Euterpe edulis Mart.). Os objetivos deste trabalho foram estimar alguns parâmetros genéticos associados à avaliação de 31 progênies de meios-irmãos de pupunheiras e classificar as melhores progênies pelo teste de médias de Scott-Knott. O delineamento experimental usado foi o de blocos ao acaso com três repetições, com parcelas experimentais de cinco plantas. As avaliações dos caracteres de altura da planta no momento do corte (APC), diâmetro da planta na altura do colo (DPC) e peso do palmito líquido (PPL) foram realizadas aos 15, 26 e 37 meses após o plantio. A população avaliada apresentou variação genética disponível para seleção e não sofreu efeito de interação com os cortes; o caráter PPL deverá ser testado com maior número de repetições, sendo o caráter mais sensível a efeitos de cortes; a razão entre o coeficiente de variação genética e o coeficiente de variação do erro indica que existem dificuldades nos processos de seleção nos caracteres avaliados; a correlação genotípica entre os caracteres DPC e PPL apresenta-se promissora para facilitar a seleção indireta do caráter PPL pelo caráter DPC. O agrupamento de médias de Scott-Knott classificou as progênies em dois grupos.
\end{abstract}

Termos para indexação: seleção, parâmetro genético, variação genética, método de melhoramento.

\section{Phenotypic and genotypic characterization in pejibayes progenies for palm heart}

\begin{abstract}
The pejibaye (Bactris gasipaes H.B.K.) is the species with the best potential in supplying the production of palm heart, in substitution to açaí (Euterpe oleracea Mart.) and juçara (Euterpe edulis Mart.) species, traditionally produced. The objectives of this work were to estimate some genetic parameters associated to the evaluation of 31 pejibayes half-sib progenies and to classify the best progenies, using the Scott-Knott test for means classification. The experimental design was a randomized complete block with three replications, and experimental plots represented by five plants. The evaluations of plant height at the moment of fell (PHF), plant diameter in the base (PDB) and net palm heart weight (PHW) were accomplished 15, 26 and 37 months after the planting. The population presented genetic variability for selection and did not suffer genotype x cut effect; the PHW character should be tested with larger replications as it was the most sensitive character to cut effects; the genetic variation coefficient and the error variation coefficient ratio indicates that there are difficulties in the selection processes for the evaluated characters; genetic correlations among the characters PDB and PHW promise to facilitate the indirect selection for PHW by using PDB. The Scott-Knott means grouping made the distinction of the progenies in two groups.
\end{abstract}

Index terms: selection, genetic parameters, genetic variation, breeding methods.

\section{Introdução}

A pupunheira (Bactris gasipaes H.B.K.) é classificada botanicamente como uma planta

(1) Aceito para publicação em 9 de setembro de 2002.

(2) Embrapa-Centro de Pesquisa Agroflorestal do Amapá, Caixa Postal 10, CEP 68902-280 Macapá, AP. E-mail: gilberto@cpafap.embrapa.br

(3) Embrapa-Centro de Pesquisa Agroflorestal da Amazônia Oriental, Trav. Enéas Pinheiro s/nọ, CEP 66095-100 Belém, PA. E-mail: tome@cpatu.embrapa.br monóica, perene, pertencente à ordem Arecalis (Mora Urpi, 1992). O palmito é formado por um conjunto de folhas imaturas, envoltas pelas bainhas das folhas mais velhas (Ferreira et al., 1976).

O crescente interesse por essa espécie se deve a suas múltiplas possibilidades de uso. Seus frutos são o principal produto na região Norte do País, apresentando-se como drupas com mesocarpo carnoso, e a farinha obtida é empregada na fabricação de pães, bolos e em rações para animais. O palmito, conside- 
rado o produto mais nobre, é muito apreciado por sua textura tenra, baixa fibrosidade, sabor suave e agradável, assim como pelo baixo teor de calorias. Por reunir tais qualidades, trata-se de um produto muito apreciado e com alto potencial de comercialização nos mercados consumidores nacionais e estrangeiros (Bovi, 1993, 1998).

O potencial da pupunheira para fornecer matériaprima ao processamento de palmito em substituição às espécies juçara (Euterpe edulis) e açaí (Euterpe oleracea), mais utilizadas pelas indústrias de palmito, deve ser avaliado, porque o extrativismo dessas espécies é realizado sem qualquer sistema de manejo. Além disso, a pupunheira apresenta, em relação ao açaí e à juçara, maiores precocidade e rusticidade, alto perfilhamento, melhor qualidade do palmito (palatabilidade, maciez e pouca fibrosidade) e não sofre escurecimento (oxidação) após o corte (Tonet et al., 1999; Chaimsohn, 2001).

Os experimentos que avaliam o potencial e as características genéticas de populações de pupunheira para fins de melhoramento genético, visando produtividade de palmito, são muito recentes, e por isso as informações disponíveis são escassas (Bovi et al., 1992).

O objetivo deste trabalho foi estimar a variabilidade de alguns parâmetros genéticos associados à avaliação de 31 progênies de meios-irmãos de pupunheira e classificar as melhores progênies, pelo teste de médias de Scott-Knott.

\section{Material e Métodos}

Os materiais genéticos avaliados foram 31 progênies de pupunheira provenientes da Embrapa-Centro de Pesquisa Agroflorestal da Amazônia Ocidental, de Manaus. As sementes foram obtidas por meio de fecundação aberta de matrizes com ausência de espinhos, sendo consideradas geneticamente como progênies de meios-irmãos.

O experimento foi instalado em uma área com solo tipo Latossolo Amarelo, textura média, topografia plana, cobertura com vegetação de capoeira, clima tipo Ami, segundo a classificação de Köppen, com temperatura média anual de $27^{\circ} \mathrm{C}$, umidade relativa do ar média de $82 \%$ e precipitação média anual de 2.700 mm, em janeiro de 1998, no Campo Experimental do Matapí, da Embrapa-Centro de Pesquisa Agroflorestal do Amapá.

O delineamento experimental foi o de blocos ao acaso, com três repetições, parcelas lineares compostas por cin- co plantas, espaçamento de 2,0x1,0 m e bordadura composta por uma fileira em torno do experimento.

Aplicaram-se $100 \mathrm{~g}$ de superfosfato triplo na cova e em cobertura, uma mistura de $110 \mathrm{~g}$ de uréia com $85 \mathrm{~g}$ de cloreto de potássio dividida em três aplicações de $65 \mathrm{~g}$. Na condução da cultura foram empregadas as recomendações preconizadas por Nogueira et al. (1995).

As progênies foram avaliadas aos 15 (corte 1), 26 (corte 2) e 37 (corte 3 ) meses pós-plantio, coletando-se dados de altura da planta no momento do corte (APC, medida do solo até o ponto de inserção da folha guia e a primeira folha expandida), diâmetro da planta na altura do colo (DPC, medida com auxílio de paquímetro) e peso do palmito líquido (PPL, palmito tipo exportação), conforme recomendações de Clement \& Bovi (2000).

Foi realizada a análise de variância em cada corte, para estimar a relação entre o maior quadrado médio do resíduo e o menor para cada corte, a fim de verificar se haveria a necessidade de ajustes de graus de liberdade das fontes de variação, para posterior análise de variância conjunta de cortes. As análises de variância, as estimativas dos parâmetros genéticos e fenotípicos, como a herdabilidade, coeficientes de variação, correlações fenotípicas e genotípicas foram efetuadas através do programa GENES, versão 2001 .0.0 (GENES..., 2001). Os procedimentos estatísticos adotados foram os de Vencovsky \& Barriga (1992). No teste de agrupamento de médias, adotou-se os procedimentos matemáticos de Scott \& Knott (1974).

O modelo matemático empregado foi:

$$
\bar{Y}_{i j}=m+G_{i}+C_{j}+G_{i j}+\bar{E}_{i j} \text {, }
$$

em que : $\overline{\mathrm{Y}}_{\mathrm{ij}}$ é o valor fenotípico médio do caráter $\mathrm{Y}$ medido no material genético $\mathrm{i}$, no corte $\mathrm{j}$; $\mathrm{m}$ é a média geral paramétrica dos dados em estudo; $\mathrm{G}_{\mathrm{i}}$ é o efeito do i-ésimo genótipo, aleatório; $\mathrm{C}_{\mathrm{j}}$ é o efeito do j-ésimo corte, aleatório; $\mathrm{GC}_{\mathrm{ij}}$ é o efeito da interação do i-ésimo genótipo com o j-ésimo corte, aleatório; $\overline{\mathrm{E}}_{\mathrm{ij}}$ é o erro médio associado à observação $\mathrm{Y}_{\mathrm{ij}}$, aleatório.

$\mathrm{O}$ efeito de blocos foi adicionado ao resíduo. Considerou-se como aleatório o efeito de progênies ou genótipos, pois os materiais foram obtidos de polinização aberta entre as diversas plantas matrizes, e o efeito de cortes, pois não foram realizados em datas predeterminadas.

\section{Resultados e Discussão}

Na idade de corte 3, houve amplificação da expressão das diferenças genéticas existentes entre as progênies, e as datas de cortes possibilitaram maior distinção, proporcionando aos caracteres avaliados estimativas maiores de coeficiente de variação gené- 
tica $\left(\mathrm{CV}_{\mathrm{g}} \%\right)$ em comparação aos obtidos nos cortes 1 e 2 (Tabela 1). Quanto ao caráter PPL, que apresentou as maiores estimativas, os valores podem ser considerados como médios (entre 17,06 e 27,22), não comprometendo a precisão dos dados experimentais, sendo um pouco maior do que o observado por Farias Neto (1999) e abaixo dos valores para peso de palmito dos trabalhos de Bovi et al. (1992, 1993), podendo-se considerar que os valores são apenas indicativos da presença de maior variação para o caráter PPL em relação aos caracteres APC e DPC.

As estimativas do coeficiente herdabilidade $\left(\mathrm{h}^{2}\right)$, nos cortes 1 e 3 , podem ser consideradas como médias, indicando que os caracteres apresentaram forte controle genético e têm grandes possibilidades de serem transmitidos para gerações futuras. No corte 2 , as estimativas de $\mathrm{h}^{2}$ foram menores para os três caracteres, reflexo dos valores obtidos dos quadrados médios das progênies e do resíduo, indicando que ocorreram efeitos de condições não genéticas, provavelmente ambientais, com maior contribuição em relação à genética.

As relações entre o maior e o menor quadrado médio dos resíduos das análises de variância por corte foram de 4,279, 1,725 e 2,717, respectivamente, para APC, DPC e PPL, indicando que não houve discrepância entre as precisões experimentais, por serem menores que sete, o que, segundo Pimentel-Gomes (1991), permite a realização da análise conjunta sem ajuste dos graus de liberdade (Tabela 2).

$\mathrm{O}$ efeito de blocos (repetições) e o efeito da interação cortes $\mathrm{x}$ blocos foram adicionados ao resíduo, principalmente por não haver interesse em se avaliar o efeito destas fontes de variações. Com o

Tabela 1. Parâmetros genéticos dos caracteres altura da planta no corte (APC), diâmetro da planta na altura do colo (DPC) e peso do palmito líquido (PPL), envolvendo 31 progênies de pupunheiras (Bactris gasipaes), nos cortes realizados em 1999 (corte 1), 2000 (corte 2) e 2001 (corte 3). Macapá, AP, 2002.

\begin{tabular}{cccccccc}
\hline Cortes $^{(1)}$ & \multicolumn{3}{c}{$\mathrm{CV}_{\mathrm{g}}(\%)$} & & \multicolumn{3}{c}{$\mathrm{h}^{2}$} \\
\cline { 2 - 4 } \cline { 6 - 8 } & APC & DPC & PPL & & APC & DPC & PPL \\
\hline 1 & 8,46 & 6,15 & 17,06 & & 0,51 & 0,42 & 0,42 \\
2 & 8,49 & 5,94 & 24,65 & & 0,16 & 0,01 & 0,39 \\
3 & 9,69 & 6,95 & 27,22 & & 0,42 & 0,33 & 0,53 \\
\hline
\end{tabular}

(1) As avaliações foram efetuadas aos 15, 26 e 37 meses após o plantio, nos cortes 1,2 e 3 , respectivamente; $\mathrm{CV}_{\mathrm{g}}(\%)$ : coeficiente de variação genética; $\mathrm{h}^{2}$ : herdabilidade média. acréscimo efetuado, o grau de liberdade do resíduo mudou de 180 para 186 , refletindo maior precisão do teste F (Tabela 2). Os tratamentos apresentaram valores significativos para o teste $\mathrm{F}$, indicando que as progênies comportaram-se de maneira diferenciada, o que beneficia o processo do melhoramento e, indiretamente, os agricultores, já que indica a existência de variabilidade para seleção dos indivíduos superiores, aumentando a média populacional posterior.

Não foi detectado efeito de cortes para o caráter PPL, ou seja, este caráter sofre menos influência das datas de corte que os demais, podendo ser interessante pela manutenção dos níveis de produtividade de palmito em vários cortes. Cuidados devem ser observados, pois são necessários mais testes para comprovação antes de qualquer recomendação.

Quanto ao efeito da interação entre genótipo e corte ( $\mathrm{GxC}$ ), não foram detectadas diferenças significativas entre as progênies para os três caracteres avaliados nos diferentes cortes e não ocorreu melhoria do desempenho de uma progênie em relação a outra com a alteração da data de corte. Isso indica que a espécie apresenta suficiente adaptação fenotípica para manter suas características mesmo com o passar do tempo, fato que pode ser interessante, pois, ao se selecionar uma progênie de alta produtividade, a tendência é de manutenção dos níveis de produção, mesmo após vários cortes.

Todos os caracteres apresentaram herdabilidades médias que podem ser utilizadas nos processos de melhoramento, pois são indicativos de que as quali-

Tabela 2. Resumo da análise de variância conjunta com os valores e significâncias dos quadrados médios dos caracteres altura da planta no corte (APC), diâmetro da planta na altura do colo (DPC) e peso do palmito líquido (PPL), envolvendo 31 progênies de pupunheiras (Bactris gasipaes), nos anos de 1999, 2000 e 2001. Macapá, AP, $2002^{(1)}$

\begin{tabular}{lrccc}
\hline Fonte de variação & \multicolumn{1}{c}{ GL } & \multicolumn{1}{c}{ APC } & DPC & \multicolumn{1}{c}{ PPL } \\
\hline Genótipos (G) & 30 & $0,095^{*}$ & $1,044^{* *}$ & $8217,011^{*}$ \\
Cortes (C) & 2 & $38,282^{* * *}$ & $42,692^{* *}$ & $1406,527^{\text {ns }}$ \\
GxC & 60 & $0,050^{\text {ns }}$ & $0,489^{\text {ns }}$ & $4199,834^{\text {ns }}$ \\
Resíduo & 186 & 0,042 & 0,511 & 3391,910 \\
\hline Total & 278 & & & \\
\hline Média & & 2,102 & 10,813 & 231,108 \\
\hline CV $_{\mathrm{e}}(\%)$ & & 9,697 & 6,609 & 25,200 \\
\hline
\end{tabular}

${ }^{(1)} \mathrm{CV}_{\mathrm{e}}$ : coeficiente de variação estatística. ${ }^{\text {ns Não-significativo. } * \mathrm{e} * * \text { Sig- }}$ nificativo a $5 \%$ e a $1 \%$ de probabilidade, respectivamente. 
dades superiores encontradas podem ser transmitidas para gerações futuras. Isto significa que os melhores indivíduos selecionados nesta geração apresentam a tendência de transferirem seus níveis de produtividade para as próximas gerações, mantendo, com isso, pelo menos, os mesmos patamares de produtividade (Tabela 3 ). Os valores obtidos neste trabalho foram bem superiores aos estimados por Farias Neto \& Resende (2001) e também aos de Farias Neto (1999), que obteve estimativas de $37 \%$ para APC, $30 \%$ para DPC e $30 \%$ para PPL, aos 15 meses de idade.

A razão $\mathrm{CV}_{\mathrm{g}} / \mathrm{CV}_{\mathrm{e}}$ pode ser empregada como um índice indicativo do grau da facilidade de seleção das progênies para cada caráter. Quando a razão estimada for igual ou maior que 1,0 , tem-se uma situação muito favorável para o processo de seleção; ou seja, a variação genética disponível é a maior responsável pelos valores de CV estimados dos dados experimentais. No experimento, todos os resultados foram menores que $1,0(0,35$ e 0,36$)$, indicando que o processo de seleção deverá ser realizado de maneira criteriosa, empregando-se procedimentos estatístico-genéticos com sensibilidade suficiente. Uma solução teórica seria o uso de maior número de repetições, que poderia causar a redução no $\mathrm{CV}_{\mathrm{e}}$, e com isso a relação $\mathrm{CV}_{\mathrm{g}} / \mathrm{CV}_{\mathrm{e}}$ poderia aumentar. Também poderia ocorrer aumento na variância e assim não seria alcançado o resultado necessário. No entanto, os valores de $\mathrm{CV}_{\mathrm{e}}$ para APC e DPC foram baixos (Tabela 3), indicando que o número de repetições e a precisão experimental foram bons, e que talvez o aumento da variabilidade genética através da introdução de novos materiais seja o mais adequado para futuros processos de melhoramento.

Tabela 3. Parâmetros genéticos da análise conjunta em relação aos caracteres altura da planta no corte (APC), diâmetro da planta na altura do colo (DPC) e peso do palmito líquido (PPL), envolvendo 31 progênies de pupunheiras (Bactris gasipaes), nos anos de 1999, 2000 e 2001. Macapá, AP, 2002.

\begin{tabular}{lccr} 
Parâmetro $^{(1)}$ & APC & \multicolumn{1}{c}{ DPC } & \multicolumn{1}{c}{ PPL } \\
\hline Variância genética & 0,005 & 0,062 & 446,35 \\
Variância resíduo & 0,042 & 0,511 & 3391,91 \\
$\mathrm{~h}^{2} \%$ (média) & 47,27 & 53,18 & 48,89 \\
$\mathrm{CV}_{\mathrm{g}}(\%)$ & 3,36 & 2,30 & 9,14 \\
$\mathrm{CV}_{\mathrm{e}}(\%)$ & 9,70 & 6,61 & 25,20 \\
Razão CV $_{\mathrm{g}} / \mathrm{CV}_{\mathrm{e}}$ & 0,35 & 0,35 & 0,36 \\
\hline
\end{tabular}

${ }^{(1)} \mathrm{h}^{2}$ : herdabilidade média; $\mathrm{CV}_{\mathrm{g}}$ : coeficiente de variação genética; $\mathrm{CV}_{\mathrm{e}}$ : coeficiente de variação estatística.
O coeficiente de variação genética foi baixo pelo fato de as progênies terem sido selecionadas antes da instalação do experimento. As progênies foram obtidas de populações já melhoradas por instituições de pesquisa, reduzindo a variabilidade genética que existe comparativamente em populações naturais. Apesar deste fato, as progênies apresentaram variabilidade genética disponível para seleção.

A discussão das correlações foi realizada com base nas estimativas genotípicas, cujos componentes são apenas os fatores genéticos das progênies (Tabela 4). A correlação entre DPC e PPL $(0,860)$, que concorda com a obtida por Farias Neto (1999), foi maior que entre APC e PPL $(0,629)$. Isto indica que a associação entre os caracteres DPC e PPL pode ser útil ao processo de melhoramento, pois facilita o processo de seleção indireta da produtividade pelo diâmetro da planta à altura do colo, cuja avaliação no campo é mais fácil que a pesagem do palmito, processo que demanda muita mão-de-obra e tempo. Estes resultados confirmam as correlações positivas e significativas encontradas entre caracteres vegetativos (diâmetro) com componentes diretos da produção (peso, diâmetro e comprimento do palmito) por Bovi et al. (1988, 1992, 1993), Clement et al. (1988) e Gomes \& Arkcoll (1988).

A correlação positiva entre APC e PPL mostra que plantas mais altas, de mesma idade biológica, apresentam maiores produções de palmito. A partir de certo nível, esta associação pode se tornar indesejável, pois quanto maior o crescimento em altura da planta, o processo de corte do palmito vai se tornando mais trabalhoso, por produzir um volume maior de material indesejável (parte do estipe descartado), induzindo em alguns casos à realização de

Tabela 4. Correlações fenotípicas e genotípicas dos caracteres altura da planta no corte (APC), diâmetro da planta na altura do colo (DPC) e peso do palmito líquido (PPL), envolvendo 31 progênies de pupunheiras (Bactris gasipaes), nos anos de 1999, 2000 e 2001. Macapá, AP, 2002.

\begin{tabular}{lccl}
\hline Caráter & APC & DPC & PPL \\
\hline APC & - & $0,359^{*(1)}$ & $0,572^{* *(1)}$ \\
& & $0,081^{\mathrm{ns}}$ & $0,629^{* *}$ \\
DPC & & - & $0,701^{* *(1)}$ \\
& & & $0,860^{* *}$ \\
\hline
\end{tabular}

${ }^{(1)}$ Correlações fenotípicas. ${ }^{\text {ns Não-significativo. } * \mathrm{e}^{* *} \text { Significativo a } 5 \% \text { e }}$ a $1 \%$ de probabilidade, respectivamente. 
duas alturas de corte, uma para retirar o estipe todo e outra para separar a parte improdutiva da que contém o palmito. Com isso, o mais indicado seriam valores de correlações negativas, em que plantas mais baixas produziriam maior quantidade de palmito. A correlação entre APC e DPC indicou que nem sempre as maiores plantas em altura apresentam caules mais grossos, podendo ocorrer tanto a presença de plantas altas ou baixas com estipes finos ou grossos. Deste modo, a seleção indireta de um caráter em função do outro poderia acarretar a escolha de materiais inadequados para a condução no campo.

Com relação ao APC, na comparação entre médias pelo teste de Scott-Knott, o grupo superior, indicado pela letra "a", é o que engloba as plantas mais altas, mas nem sempre é o mais desejado nos plantios, por dificultar possíveis procedimentos de colheita do palmito (Tabela 5). Porém, a correlação genotípica encontrada indica que este caráter é associado positivamente com PPL. Assim, verifica-se a necessidade de um estudo mais detalhado de seleção, a fim de discriminar a presença de segregantes transgressivos que consigam quebrar esta correlação, apresentando plantas baixas com alto valor de PPL.

Quanto ao caráter DPC, o grupo "a" é de maior interesse por representar as progênies com maior diâmetro de estipe. Este grupo apresentou 14 progênies ( $45 \%$ do total), ou seja, foi o grupo que apresentou as melhores progênies para o programa de seleção. Em relação ao caráter PPL, o grupo "a”, formado pelas progênies de maior produtividade, as quais não diferiram significativamente entre si, foi composto por 21 (68\% do total) das 31 progênies testadas, com médias variando de 299,23 g a 225,56 g, devendo ser preferidas nos processos de seleção. Um comparativo de PPL com a classificação em DPC pode indicar que ocorreu coincidência entre os melhores desempenhos para ambos os caracteres, confirmando o resultado de correlação genética. Quanto ao PPL, as progênies do grupo "b", apesar de serem consideradas inferiores, somente deverão ser descartadas se não apresentarem outras características importantes em futuros processos de melhoramento, como por exemplo, resistência a pragas e doenças, alta precocidade e melhor perfilhamento.

Estudos genéticos aprofundados devem ser realizados sobre as progênies disponíveis no campo
Tabela 5. Classificação e médias dos caracteres altura da planta no corte (APC), diâmetro da planta na altura do colo (DPC) e peso do palmito líquido (PPL), de 31 progênies de pupunheiras (Bactris gasipaes), nos anos de 1999 . 2000 e 2001. Macapá, AP, $2002^{(1)}$.

\begin{tabular}{|c|c|c|c|c|c|}
\hline \multicolumn{2}{|c|}{ APC } & \multicolumn{2}{|c|}{ DPC } & \multicolumn{2}{|c|}{ PPL } \\
\hline Progênie & Média & Progênie & Média & Progênie & Média \\
\hline 11 & $2,32 \mathrm{a}$ & 2 & $11,73 a$ & 7 & $299,23 a$ \\
\hline 5 & $2,27 \mathrm{a}$ & 18 & $11,56 \mathrm{a}$ & 13 & $279,55 a$ \\
\hline 25 & $2,24 \mathrm{a}$ & 13 & $11,32 \mathrm{a}$ & 18 & $276,33 a$ \\
\hline 29 & $2,23 \mathrm{a}$ & 7 & $11,17 \mathrm{a}$ & 25 & $270,00 \mathrm{a}$ \\
\hline 13 & $2,23 a$ & 5 & $11,11 \mathrm{a}$ & 14 & $255,77 \mathrm{a}$ \\
\hline 18 & $2,20 \mathrm{a}$ & 28 & $11,06 \mathrm{a}$ & 17 & $254,33 a$ \\
\hline 6 & $2,18 \mathrm{a}$ & 15 & $11,04 \mathrm{a}$ & 5 & $252,33 a$ \\
\hline 22 & $2,17 \mathrm{a}$ & 6 & $11,01 \mathrm{a}$ & 24 & $251,44 a$ \\
\hline 14 & $2,17 \mathrm{a}$ & 20 & $10,96 a$ & 2 & $251,00 \mathrm{a}$ \\
\hline 7 & $2,17 \mathrm{a}$ & 9 & $10,91 \mathrm{a}$ & 15 & $246,00 \mathrm{a}$ \\
\hline 17 & $2,14 \mathrm{a}$ & 25 & $10,90 \mathrm{a}$ & 20 & $240,89 a$ \\
\hline 15 & $2,13 \mathrm{a}$ & 11 & $10,90 \mathrm{a}$ & 22 & $240,11 a$ \\
\hline 19 & $2,12 \mathrm{a}$ & 24 & $10,89 \mathrm{a}$ & 8 & $239,89 a$ \\
\hline 30 & $2,11 \mathrm{a}$ & 16 & $10,88 \mathrm{a}$ & 19 & $238,11 \mathrm{a}$ \\
\hline 4 & $2,11 \mathrm{a}$ & 8 & $10,82 b$ & 6 & $235,33 a$ \\
\hline 24 & $2,10 \mathrm{~b}$ & 17 & $10,81 b$ & 11 & $234,33 \mathrm{a}$ \\
\hline 1 & $2,09 \mathrm{~b}$ & 3 & $10,76 \mathrm{~b}$ & 3 & $233,67 a$ \\
\hline 2 & $2,08 \mathrm{~b}$ & 14 & $10,73 b$ & 9 & $231,44 a$ \\
\hline 9 & $2,07 \mathrm{~b}$ & 21 & $10,71 b$ & 16 & $226,22 a$ \\
\hline 8 & $2,07 \mathrm{~b}$ & 29 & $10,68 b$ & 29 & $225,89 a$ \\
\hline 26 & $2,06 \mathrm{~b}$ & 30 & $10,63 b$ & 28 & $225,56 a$ \\
\hline 16 & $2,04 \mathrm{~b}$ & 1 & $10,58 b$ & 30 & $209,78 b$ \\
\hline 28 & $2,03 \mathrm{~b}$ & 10 & $10,57 \mathrm{~b}$ & 12 & $207,89 b$ \\
\hline 12 & $2,03 b$ & 27 & $10,56 b$ & 23 & $204,11 b$ \\
\hline 3 & $2,03 \mathrm{~b}$ & 23 & $10,54 b$ & 31 & $203,11 b$ \\
\hline 21 & $2,02 \mathrm{~b}$ & 12 & $10,50 \mathrm{~b}$ & 10 & $199,78 b$ \\
\hline 23 & $1,99 \mathrm{~b}$ & 19 & $10,49 b$ & 27 & $194,67 b$ \\
\hline 31 & $1,98 \mathrm{~b}$ & 22 & $10,41 b$ & 26 & $194,22 b$ \\
\hline 20 & $1,93 \mathrm{~b}$ & 31 & $10,33 b$ & 1 & $189,22 b$ \\
\hline 10 & $1,93 \mathrm{~b}$ & 4 & $10,33 b$ & 4 & $180,33 b$ \\
\hline 27 & $1,90 \mathrm{~b}$ & 26 & $10,31 b$ & 21 & $173,78 b$ \\
\hline
\end{tabular}

(1)Em cada coluna, médias seguidas da mesma letra não diferem entre si pelo teste de Scott-Knott a 5\% de probabilidade.

experimental, pois a existência de variabilidade genética possibilita encontrar ao menos um indivíduo que poderá servir de base para cruzamentos futuros.

\section{Conclusões}

1. Existe variabilidade genética para seleção entre as progênies avaliadas.

2. As progênies não sofrem os efeitos da interação do tipo genótipo x cortes, e são estáveis para estas condições.

3. O caráter PPL, por ser o mais sensível aos efeitos de cortes, necessita ser testado com maior número de repetições.

4. A razão $\mathrm{CV}_{\mathrm{g}} / \mathrm{CV}_{\mathrm{e}}$ indica que a seleção deve ser realizada com base em processos criteriosos e com 
sensibilidade adequada nos três caracteres avaliados.

5. A correlação entre DPC e PPL apresenta-se promissora na seleção indireta do caráter PPL pelo DPC.

6. O teste de Scott-Knott propicia a distinção das progênies em dois grupos de classificação em relação aos caracteres avaliados.

\section{Referências}

BOVI, M. L. A. Palmito pupunha: informações básicas para cultivo. Campinas: Instituto Agronômico, 1998. 50 p. (IAC. Boletim Técnico, 173).

BOVI, M. L. A. Palmito pupunha: informações básicas para o cultivo. In: ENCONTRO SOBRE PRODUÇÃO DE PALMITO, 1993, Piracicaba. Anais... Piracicaba: Fealq, 1993. p. 12-23.

BOVI, M. L. A.; GODOY JÚNIOR, G.; CAMARGO, S. B.; SPIERING, S. H. Caracteres indiretos na seleção de pupunheiras inermes (Bactris gasipaes H. B. K.) para palmito. In: CONGRESSO INTERNACIONAL SOBRE BIOLOGIA, AGRONOMIA E INDUSTRIALIZACIÓN DEL PIJUAYO, 4., 1991, Iquitos. Anais... San José: Universidad de Costa Rica, 1993. p. 163-176.

BOVI, M. L. A.; GODOY JÚNIOR, G.; SAES, L. A. Pesquisas com os gêneros Euterpe e Bactris no Instituto Agronômico de Campinas. In: ENCONTRO NACIONAL DE PESQUISADORES DE PALMITO, 1., 1987, Curitiba. Anais... Curitiba: Embrapa-CNPF, 1988. p. 1-43. (Documentos, 19).

BOVI, M. L. A.; SAES, L. A.; GODOY JÚNIOR, G Correlações fenotípicas entre caracteres não destrutíveis e palmito em pupunheiras. Turrialba, San José, v. 42, n. 3 , p. 382-390, 1992.

CHAIMSOHN, F. P. Cultivo de pupunha para palmito: importância, mercado e aspectos biológicos e agronômicos. In: INTRODUÇÃO ao cultivo de palmeira real para palmito. Londrina: Instituto Agronômico do Paraná, 2001. p. 4-19 (Circular Técnica, 117). Curso sobre cultivo e processamento de palmito de pupunha.

CLEMENT, C. R.; BOVI, M. L. A. Padronização de medidas de crescimento e produção em experimento com pupunheira para palmito. Acta Amazonica, Manaus, v. 30, n. 3, p. 349-362, 2000.

CLEMENT, C. R.; CHÁVEZ FLORES, W. B.; GOMES, J. B. M. Considerações sobre a pupunha (Bactris gasipaes H. B. K.) como produtora de palmito. In: ENCONTRO NACIONAL DE PESQUISADORES DE PALMITO, 1.
1987, Curitiba. Anais... Curitiba: Embrapa-CNPF, 1988. p. 225-247 (Documentos, 19).

FARIAS NETO, J. T. Estimativas de parâmetros genéticos em progênies de meios-irmãos de pupunheira. Boletim de Pesquisa Florestal, Colombo, v. 39, p. 109-117, 1999.

FARIAS NETO, J. T.; RESENDE, M. D. V. Aplicação da metodologia de modelos mistos (REML/BLUP) na estimação de componentes de variância e predição de valores genéticos em pupunheira (Bactris gasipaes). Revista Brasileira de Fruticultura, Jaboticabal, v. 23, p. 320-324, 2001.

FERREIRA, V. L. P.; MIYA, E. E.; SHIROSE, I.; ARANHA, C.; SILVA, E. A. M.; HIGHLANDS, M. E. Comparação físico-químico-sensorial de três espécies de palmito. Coletânea do Instituto de Tecnologia de Alimentos, Campinas, v. 7, n. 2, p. 389-416, 1976.

GENES - programa para análise e processamento de dados baseado em modelos de genética e estatística experimental: versão 2001.0.0. Viçosa, MG: UFV, 2001. 1 CD-ROM.

GOMES, J. B. M.; ARKCOLL, D. B. Estudos iniciais sobre a produção de palmito de pupunha. In: ENCONTRO NACIONAL DE PESQUISADORES DE PALMITO, 1., 1987, Curitiba. Anais... Curitiba: Embrapa-CNPF, 1988. p. 271-278. (Documentos, 19).

MORA URPI, J. Pejibaye (Bactris gasipaes). In: HERNADEZ BERMEJO, J. E.; LEON, J. (Ed.). Cultivos marginados: outra perspectiva de 1942. Roma: FAO, 1992. p. 209-219.

NOGUEIRA, O. L.; CALZAVARA, B. B. G.; MULLER, C. H.; CARVALHO, C. J. R. de; GALVÃO, E. U. P.; SILVA, H. M.; RODRIGUES, J. E. L. F.; CARVALHO, J. E. V. de; OLIVEIRA, M. do S. P. de; ROCHA NETO, O. G. de; NASCIMENTO, W. M. O. do. A cultura da pupunheira. Brasília: Embrapa-SPI, 1995. 50 p. (Coleção Plantar, 25).

PIMENTEL-GOMES, F. Análise de grupos de experimentos. In :- (Ed.). Curso de estatística experimental. 14. ed. Piracicaba: Nobel, 1991. p. 168-197.

SCOTT, A. J.; KNOTT, M. A. A cluster analysis method for grouping means in the analysis of variance. Biometrics, Washington, v. 30, p. 507-512, 1974.

TONET, R. M.; FERREIRA, L. G de S.; OTOBONI, J. L. de M. A cultura da pupunha. Campinas: Coordenadoria de Assistência Técnica Integral, 1999. 44 p. (Boletim Técnico, 237).

VENCOVSKY, R.; BARRIGA, P. Genética biométrica no fitomelhoramento. Ribeirão Preto: Sociedade Brasileira de Genética, 1992. 496 p. 